\title{
Vorwort zur zweiten und dritten Auflage
}

Die erste Auflage dieses Lexikons war schnell vergriffen. Zahlreiche Zuschriften aus dem Leserkreis bekundeter ein breites Interesse, so daß sich bald der Entschluß zu einer Neuauflage festigte. Dabei erfolgten neben verschiedentlichen Verbesserungen insbesondere Abrundungen und auch thematische Erweiterungen. Neu hinzugekommen sind außerdem (im Anschluß an den Artikelteil) tabellarische Zusammenstellungen für die gebräuchlichsten Verteilungen und für die wichtigstèn Tests sowie alphabetisch angeordnete Sachregister der im Lexikon enthaltenen Artikel in Englisch, Französisch und Russisch mit den entsprechenden deutschsprachigen Bezeichnungen. Des weiteren wurde eine Ubersicht vorangestellt, die einerseits den in Teilgebieten gegliederten stofflichen Inhalt des Lexikons kennzeichnet, andererseits bei Benutzung des Lexikons zur systematischen Lektüre die gegenseitige Abhängigkeit und logische Reihenfolge der in Frage kommenden Artikel erkennen läßt. Die 3. Auflage enthält zusätzlich Angaben über einige in den letzten Jahren erschienene Bücher.

Die vorliegende neue Fassung des Lexikons resultiert aus der Zusammenarbeit eines gegenüber der ersten Auflage noch um einige erfahrene Mitarbeiter erweiterten Autorenkollektivs. Darüber hinaus wurde die Bearbeitung durch vielfältige Anregungen und direkte Unterstützung aus dem Kreis der Leser und insbesondere der Fachkollegen gefördert, wofür allen Beteiligten an dieser Stelle herzlich gedankt sei. Dank gebührt ebenfalls Fräulein Dipl.-Math. R. HELlE, die auch diesmal die redaktionelle Betreuung des Titels beim Akademie-Verlag in bewährter Weise wahrnahm.

Insgesamt hoffen wir, neben der erfolgten umfangmäßigen Erweiterung auch eine inhaltliche Vervollkommnung im Sinne der im Vorwort zur ersten Auflage genannten Zielstellung des Lexikons erreicht zu haben. 